\title{
PRIMARY RENAL TUMOURS IN CHILDHOOD
}

\author{
By L. Stuart ScotT, Ch.M., F.R.C.S.Ed., F.R.F.P.S. \\ Urological Department, Western Infirmary, and Royal Beatson Memorial Hospital, Glasgow; formerly, Royal Hospital \\ for Sick Children, Glasgow
}

Although practically every form of tumour found in the adult kidney has been reported in childhood, the overwhelming majority of primary renal tumours in childhood are embryomata (syn: Wilms' tumour).

Benign renal tumours are rare in children. Adenomata seldom cause symptoms and are generally discovered at autopsy. Fibromata are usually small and sub-capsular but may grow slowly over a period of many years. One such tumour was noted by Rush and Rush (1933) in a child aged 7 years which, because of pressure symptoms due to steady enlargement, was successfully removed 14 years later. Lipomata have not apparently been described in this age group but small angiomata have occasionally been the cause of persistent haematuria (Scott, I954).

Malignant tumours of the kidney, other than embryomata, are extremely rare in children, although 14 cases of clear-cell carcinoma were collected by Currie (I955).

\section{Embryoma (Wilms' Tumour) \\ Incidence}

Renal tumours cause 0.07 per cent. of the total deaths and 17 per cent. of the tumour-deaths in children under twelve (Scott, I956). They represented 2 I per cent. of Ioo consecutive malignant tumours examined at the Royal Hospital for Sick Children, Glasgow (Scott, r954), and accounted for I in 3,000 admissions to this hospital. Although they are the commonest tumours of the urinary tract in this age group, the relative incidence of renal tumours in childhood to that of adult life is only i : 4 .

\section{Familial Incidence}

Maslow (1940) reported three cases and a probable fourth in one family. Gaulin (I95I) found mirror-image embryomata in identical twins and a familial occurence has also been noted by Chapian (1948), Fitzgerald and Hardin (1954), and De Vries (1954).

\section{Age}

The vast majority appear within the first four

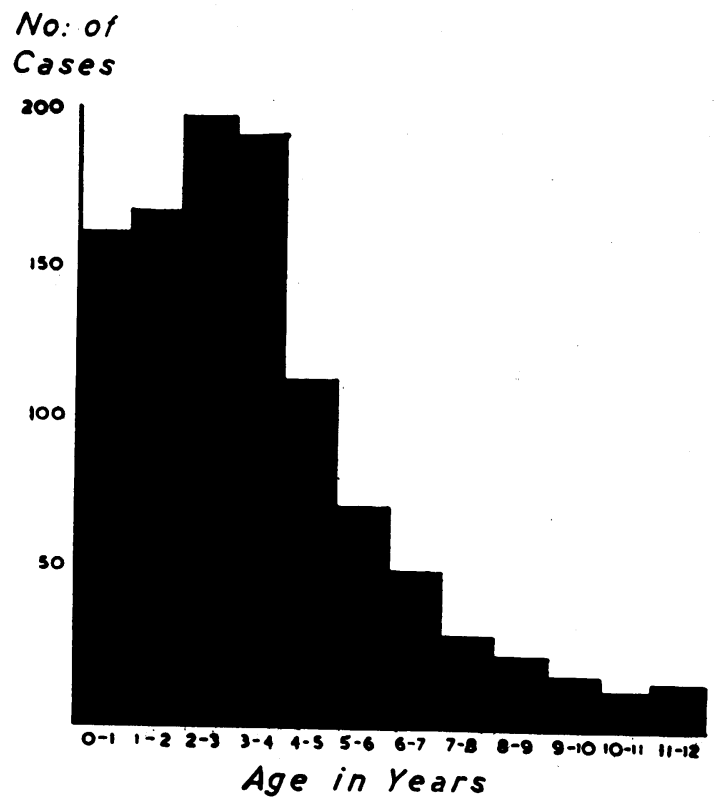

years of life (Fig. I) and they have been reported in the foetus. I have encountered one in a stillborn child and two in adults. They are relatively rare in adults but Culp and Hartman (1948) collected 97 cases from the literature.

\section{Sex and Side}

There is no significant difference in either of these factors. In 706 cases (Scott, I955 b) I found 370 males and 336 females. The growth was in the right kidney in 46.1 per cent., the left in 50.3 per cent., and was bilateral in 3.6 per cent. At that time (Scott, I955a) I pointed out that the incidence of bilateral involvement was higher than was generally appreciated; this has recently been corroborated by Feeney et al. (I955).

\section{Morbid Anatomy}

These tumours may originate in any part of the renal parenchyma, but the exact site of inception is generally indeterminable. They may be ovoid, 
globular or nodular and may vary in size from an orange up to a weight of $36 \mathrm{lb}$. Their consistency is generally like that of brain tissue and they appear to be 'surrounded' by a pseudo-capsule of fibrous tissue. Areas of degeneration, necrosis, liquification and haemorrhage are the rule. The surface vessels are grossly dilated and, on hemisection, the renal parenchyma is frequently compressed into a narrow ' rind.' The renal pelvis may be narrowed, dilated, elongated, or otherwise distorted, but is seldom invaded, although Watkins (1957) described a case with extension into renal pelvis, continuing down the ureter into bladder.

Metastases are both lymph and blood borne, the commonest sites being the lungs and abdominal lymph glands but no tissue appears to be immune. Renal vein involvement is not as common as with the adult carcinoma.

\section{Histology}

The histological appearances are so varied that its terminology has included adenorhabdomyosarcoma, nephroblastoma, embryonal sarcoma and fibroadenorhabdomyomatous mesothelioma; indeed, Culp and Hartman (1948) found 53 different designations in the literature. They suggest the name embryonal nephroma for the whole group but subdivide them into mixed-cell, undifferentiated, carcinomatous and sarcomatous types, and put forward the view that they all have a common pathogenesis with a common origin as mixed-cell tumours.

Embryonic mesoblastic tissue constitutes the bulk of the tumour and presents as diffuse sheets or masses of cells. Occasionally the cells are arranged as primitive tubules or glomeruli and striated muscle fibres are common. Contrary to the naked-eye appearance, microscopy confirms that they are not completely confined by the pseudo-capsule; instead, the neoplastic cells can be seen irregularly infiltrating the adjacent parenchyma.

The presence of other tissues have frequently been reported but, as I have previously pointed out (Scott, 1954), the use of the word teratoma as a synonym for embryoma is quite incorrect as these very rare renal teratomata constitute a separate pathological entity in which all three germ layers are represented.

\section{Symptoms}

Most of these cases present with a firm, palpable swelling which is generally discovered accidentally by the child's mother at bathtime. Although haematuria is present in about 20 per cent., the classical triad of swelling, pain and haematuria-so commonly found in adults-is present in only about to per cent. Urinary symptoms are con- spicuous by their absence but nausea, anorexia, lassitude and a slight fever are not uncommon. Pain was not common in the cases that I studied but Abeshouse (1957) noted its presence in 30 per cent.

\section{Radiological Findings}

Excretion pyelography is an essential preoperative measure as it demonstrates the presence and degree of function of the other kidney. The definition obtained by intravenous diadone is generally sufficient to obviate the need for retrograde pyelography and, although the latter may be necessary when the tumour is in a non-functioning kidney, pre-operative handling of the child's abdomen should be reduced to an absolute minimum; retrograde pyelography being used as seldom as possible. If technical difficulties prevent the use of the intravenous route, the dye can be given subcutaneously (Nesbit and Douglas, 1939) or intramuscularly (Adams and Hunt, r939). Non-function, hydronephrosis and calyceal distortion are the commonest changes seen.

\section{Differential Diagnosis}

Embryomata are most frequently confused with sympathicoblastoma and congenital hydronephrosis, but splenomegaly, polycystic disease, intrå abdominal cysts, leukaemic kidneys and lymphos sarcoma have all to be considered. Recentlye Traggis and Ellison (1956) have suggested that unilateral renal-vein thrombosis should also be considered.

\section{Treatment}

There is, at present, no uniformity of opinion about the management of these cases and a vast number of different procedures have been advocated.

Prior to the advent of radiotherapy, they were all 3 treated by nephrectomy alone, with fairly disas- $\dot{\sigma}$ trous results, although Ladd and White (194I) attained a 24 per cent. survival rate. In spite of $\delta$ the plea by Abeshouse (1957) for the continued use $₹$ of this method in selected cases, most authorities $ᄋ$ agree that surgery and radiotherapy must go hand-in-hand to achieve any real success.

Foster and Mendilharzu (1925) implanted radium needles into the tumour, but this pro- or cedure failed to stand the test of time. Coley $\tilde{N}$ (1935) reported a 29-year survival following $\underset{\omega}{N}$ nephrectomy and post-operative injection of $\frac{\sigma}{2}$ Coley's fluid, but the method never attained popu- 0 larity. Following the radiological demonstration $\overparen{\varnothing}$ that intravenous nitrogen mustard can eliminate $\stackrel{\odot}{+}$ pulmonary metastases, Johnson and Marshall 70 (1955) gave it in doses of 0.4 to $0.8 \mathrm{mg}$. per kilo $\stackrel{\vec{D}}{\vec{D}}$ body weight in the immediate post-operative 
period, followed, two or three weeks later, by irradiation therapy to the operative site. Their results were variable and a long-term evaluation of the procedure is not yet available.

Radiotherapy by itself still has a limited place in the treatment of advanced tumours with pulmonary metastases (Kerr, I939; Silver, 1947) and in the treatment of bilateral tumours (Close et al., 1956), but if there is to be any hope of permanent cure it is now agreed that, in the absence of demonstrable metastases, the tumour mass must be excised at some stage in the treatment. The usual lumbar incision is generally inadequate for the removal of these large tumours, and a trans-abdominal exposure through a T-shaped or wide transverse incision is recommended, although some prefer a trans-thoracic approach (Chute et al., I949) or the dorso-lumbar flap exposure (Nagamatsu, 1950).

Although there is still disagreement over the therapeutic value of routine pre-operative radiotherapy, most surgeons would agree that therapy is essential in the post-operative regime. Most of these tumours are so highly radiosensitive that large, bulky and apparently inoperable tumours can be made to shrink to an 'operable' size; thus pre-operative radiotherapy may play a useful role in certain cases. Dean (1952) believes that preoperative irradiation destroys the thin-walled veins in the tumour and opens up fresh pathways of dissemination. Both he and Gross (1953) consider that the growth should be treated as a surgical emergency; certainly prompt nephrectomy combined with radiotherapy-starting immediately after operation and before recovery from the anaesthetic-has given far and away the best results yet published (Gross and Neuhauser, 1950).

The extensive use of radiotherapy in this field must never be treated lightly because of its destructive effect on leucocytes (Scott, 1956) and on the vertebrae (Whitehouse and Lampe, I953), but the effects on wound-healing are less marked in childhood and should not prevent early institution of post-operative therapy.

\section{Prognosis}

Although the prognosis has steadily improved in the past $5^{\circ}$ years, the outlook is still very poor, the two-year survival rate being about 25 to 30 per cent. The prognosis is much better if the tumour appears in the first year of life (Scott, 1956), but haematuria is associated with a very high mortality and it seems that delay in excising the tumour may also have an adverse effect.

Throughout the literature the " standard of cure' is accepted as two years of freedom from recurrence or metastases, but recent reports of distant metastases 17 years later (Nesbit, 1952) and local recurrences eight years later (Falkinburg et al., 1954) must make us review our 'survival rates' more critically in the future.

\section{BIBLIOGRAPHY}

ABESHOUSE, B. S. (I957), $\mathcal{F}$. Urol. (Baltimore), 77, 792.

ADAMS, P. S., and HUNT, H. B. (1939), Ibid., 42, 689.

CHAPIAN, M. A. (1948), R.I. med. $\mathcal{F}$., 3I, 105.

CHUTE, R., SOUTTER, L., and KERR, W. S. (1949), Nerw Engl. F. Med., 24r, $95 \mathrm{I}$

CLOSE, M. B., PETERSON, C. A., and JOHNSON, R. P. (1956), Radiology, 67, 99.

COAKLEY (1957), quoted by ABESHOUSE, B. S. (1957), loc. cit. COLEY, W. B. (1935), Ann. Surg., 29, 463.

CULP, O. S., and HARTMAN, F. W. (1948), f. Urol. (Baltimore), $60,552$.

CURRIE, J. A. (1955), S. Afr. med. F., 29, 730.

DEAN, A. L. (1952), Trans. Amer. Ass. gen.-urin. Surg., 44, 23.

FALKINBURG, le Roy, KAY, M. N., and SAYER, E. A. (1954), F. Amer. med. Ass., 155, 1228.

FEENEY, M. J., MULLENIX, R. B., PRENTISS, R. J., and WHISENAND, J. M. (1955), ₹. Urol. (Baltimore), 73, 301.

FITZGERALD, W. L., and HARDIN, H. C. (1954), quoted by ABESHOU'SE, B. S. (1957), loc. cit.

FOSTER, E., and MENDILHARZU, J. R. (I925), Sem. méd $(B$. Aires), 32, 926

GAULIN, E. (195I), F. Urol. (Baltimore), 66, 547.

GROSS, R. E. (1953), 'The Surgery of Infancy and Childhood, Saunders, Philadelphia.

GROSS, R. E., and NEUHAUSER, E. B. D. (1950), Pediatrics, 6 , 843 .

JOHNSON, S. H., and MARSHALL, M. (1955), F. Urol. (Baltimore), 74, 707

KERR, H. D. (1939), F. Amer. med. Ass., 112, 408.

LADD, W. E., and WHITE, R. R. (I94I), Ibid., II7, 1858.

MASLOW, L. A. (1940), f. Urol. (Baltimore), 43, 75.

NAGAMATSU, G. (1950), Ibid., 63, 569.

NESBIT, R. M. (1952), Trans. Amer. Ass. gen.-urin. Surg., 44, 23 NESBIT, R. M., and DOUGLAS, D. B. (1939), F. Urol. (Baltimore), 42, 709 .

RUSH, L. V., and RUSH, H. L. (1933), Amer. F. Surg., I9, 53 I. SCOTT, L. S. (1954), Glasg. med. $\mathcal{f}$., 35, 33.

SCOTT, L. S. (1955a), Brit. F. Surg., 42, 513.

SCOTT, L. S. (1955b), Ch.M. Thesis, University of Glasgow.

SCOTT, L. S. (1956), Brit. med. F., i, 200.

SILVER, H. K. (1947), f. Pediat., 3I, 643.

TRAGGIS, D. G., and ELLISON, M. M. (1956), Ibid., 48, 229.

VRIES, J. K. de (1954), F. med. Soc. N.F., 5I, i1.

WATKINS, J. P. (1957), F. Urol. (Baltimore), 77, 593.

WHITEHOUSE, W. M., and LAMPE, I. (1953), Amer. F. Roentgenol., 70, 721. 